Research Article

\title{
Prevalence and Factors Associated with Back Pain among Patients Undergoing Spinal Anesthesia at the University of Gondar Comprehensive and Specialized Hospital, North West Ethiopia: An Institutional Based Cross-Sectional Study
}

\author{
Tadael Gudayu Zeleke, Abraham Tarekegn Mersha ${ }^{D}$, Nigussie Simeneh Endalew, \\ and Yonas Admasu Ferede \\ Department of Anesthesiology and Critical Care, School of Medicine, College of Medicine and Health Science, \\ University of Gondar, Gondar, Ethiopia \\ Correspondence should be addressed to Abraham Tarekegn Mersha; abrahamtm2006@gmail.com
}

Received 25 November 2020; Revised 5 January 2021; Accepted 13 January 2021; Published 27 January 2021

Academic Editor: Rahman Shiri

Copyright ( 2021 Tadael Gudayu Zeleke et al. This is an open access article distributed under the Creative Commons Attribution License, which permits unrestricted use, distribution, and reproduction in any medium, provided the original work is properly cited.

\begin{abstract}
Background. Back pain is often reported as a common complaint after surgery. Many studies showed that the prevalence of back pain after spinal anesthesia is high and its magnitude is considerable in developing countries. It is highly related to reduced quality of life, loss of work productivity, burden of health care costs, and satisfaction regarding health care service; therefore, measures should be taken to reduce or prevented postspinal back. The aim of this cross-sectional study was to assess the prevalence and factors associated with back pain among patients undergoing spinal anesthesia at the University of Gondar Comprehensive and Specialized Hospital, Northwest Ethiopia. Methodology. An institutional based cross-sectional study was conducted from March to May 2020. A total of 215 participants were enrolled in this study. A convenience sampling technique was used to get the study participants. Both univariable and multivariable logistic regression were used to identify factors associated with postspinal back pain. Variables with a $p$ value less than $<0.2$ in the bivariable analysis were fitted into the multivariable analysis. In the multivariable analysis, a variable with a $p$ value of $<0.05$ was considered statistically significant. Results. The overall prevalence of postspinal back pain was 40.5\% (95\% CI: 34.0, 47.4). Being overweight ( $\mathrm{AOR}=3.8 ; 95 \% \mathrm{CI}: 1.47,9.96)$ and obese $(\mathrm{AOR}=4.9 ; 95 \%$ CI: 1.19, 20.4), using big spinal needles (AOR $=5.9 ; 95 \% \mathrm{CI}: 1.04,33.4)$, two attempts of lumbar puncture $(\mathrm{AOR}=5.5 ; 95 \% \mathrm{CI}: 1.74$, 17.59), more than three attempts of lumbar puncture $(\mathrm{AOR}=4.9 ; 95 \% \mathrm{CI}: 1.63,15.2)$, and the number of bone contacts during spinal anesthesia procedure ( $\mathrm{AOR}=3.1 ; 95 \% \mathrm{CI}: 1.14,8.45)$ were positively associated with postspinal back pain. Conclusion and Recommendation. The overall incidence of back pain is high. Body mass index, size of spinal needle, number of attempts, and number of bone contacts are significantly associated with the incidence of back pain following spinal anesthesia. Thus, it is better to minimize the number of lumbar puncture attempts and bone contacts during spinal anesthesia to reduce postspinal back pain. In addition, using smaller size spinal needle is a good choice.
\end{abstract}

\section{Introduction}

Spinal anesthesia (SA) is the most commonly preferred and widely used anesthesia technique in surgeries like lower extremity surgery, anorectal, urologic, obstetric, and gynecologic interventions and lower abdominal procedures. [1,2] Even though spinal anesthesia is the preferred technique, it has a lot of complications like postspinal back pain (PSBP) compared to general anesthesia (GA). [2-6].

Back pain is a worldwide health problem affecting $50 \%$ and $80 \%$ of people at some time in their lives and it is a major physical and economical burden for the individual and the society [7-10]. The lifetime incidence of nonspecific low back pain is more than $84 \%$, the incidence of chronic low 
back pain is about $23 \%$, and $11-12 \%$ of the population suffered disability with this pain [11].

Regardless of the anesthetic technique, postoperative low back pain is often reported as a common complaint after SA but the association between anesthetic technique and back pain is still unclear [12]. Postspinal back pain (PSBP) is usually a mild type of pain and it manifests during the first two to six hours (hrs) after the surgical procedure, when the local anesthetics wear off in most people, and lasts only for a few days [5]. Rarely, the pain may persist for some weeks and becomes permanent because of nerve injury during spinal needle insertion $[13,14]$.

Studies showed the incidence of back pain ranges $10.7-12.3 \%$ after spinal anesthesia $[5,15,16]$. A study conducted in Ethiopia reported that $38.0 \%, 29.9 \%$, and $16.0 \%$ of patients suffered PSBP in the $1^{\text {st }}, 2^{\text {nd }}$, and $3^{\text {rd }}$ postoperative days after SA, respectively [4]. Another study done in Asella, Ethiopia, showed that patients suffered backache in the postoperative $1^{\text {st }}, 2^{\text {nd }}$, and $3^{\text {rd }}$ days and $4^{\text {th }}$ week after spinal anesthesia in surgical procedures with 38.0, $29.9,16.0$, and $31.6 \%$ respectively [17]. Fear of back pain after $\mathrm{SA}$ is one reason for patient refusal of this type of anesthesia and it accounts for a refusal rate of $13.4 \%[16,18]$.

In a study done in Chicago, USA, $9-10 \%$ of the study participants had postoperative back pain after SA [19]. On the other hand, in a multicenter prospective study in Europe, back pain was the leading complaint among other postlumbar puncture complaints with an incidence of $17 \%$ [20]. A higher prevalence rate, $40 \%$, of back pain after spinal anesthesia was found in a prospective observational study in Germany, on 112 patients [21]. In addition, studies done in Turkey and China showed that PSBA occurred in $29.3 \%$ of patients [1] and 39\% at the first, $37 \%$ at the second, and $31 \%$ at the third postoperative days [22] after SA, respectively.

Back pain remains the determinant factor for patient satisfaction after spinal anesthesia [23]. Apart from uncomfortable experience, untreated back pain cause side effects like aggravating wound pain by stretching incisions, increasing intracranial and intraocular pressure, increasing expenditure of cardiac and systemic energy, and increasing tissue oxygen demand and delayed discharge from postanesthetic care and also from hospitals [16]. This may be very deleterious in patients particularly those with impaired cardiovascular reserve or a limited respiratory capacity [4]. Overall, in long-term effect, postspinal back pain may be related to reduced quality of life, sickness, absence, loss of work productivity, and high health care costs [24].

Giving concise and detailed information regarding postoperative back pain after spinal anesthesia during the informed consent might improve satisfaction with the anesthetic procedure. [22] Therefore, the aim of this study is to assess the prevalence and factors associated with back pain among patients undergoing spinal anesthesia at the University of Gondar Comprehensive Specialized Hospital.

\section{Materials and Methods}

2.1. Study Setting and Population. An institutional based cross-sectional study was conducted at the University of
Gondar Comprehensive Specialized Hospital from March to May 2020. The University of Gondar Comprehensive and Specialized Hospital is one of the biggest governmental teaching hospitals which is located in Amhara region, Central Gondar Zone, about $738 \mathrm{~km}$ away from the capital city, Addis Ababa, and $230 \mathrm{~km}$ from Ethiopia-Sudan border in the North west of Ethiopia. It has been giving services for millions of patients in the region.

All patients scheduled for elective or emergency surgery under spinal anesthesia during data collection period were enrolled in this study whereas patients with preexisting back pain, patients $<16$ years, traumatic deformity of the spine or congenital abnormalities of the lumbar spine, impaired cognitive ability, and patients undergoing combined spinal and epidural anesthesia were excluded from the study.

2.2. Sample Size and Sampling Procedure. Single population proportion formula was used to determine the sample size. It was calculated by considering a $95 \%$ confidence interval, a $5 \%$ margin of error, and $38.0 \%$ as a proportion of incidence of postspinal back pain in the first day based on a study conducted in Asella, Ethiopia. [17] Then, a sample size of 362 patients was obtained. However, we used a correction formula since the study population is less than 10,000. Finally, a size of 215 was used considering a $10 \%$ nonresponse rate.

The convenience sampling technique was used in all patients undergoing surgical operation under spinal anesthesia at the University of Gondar Comprehensive Specialized Hospital until the required sample size was reached.

\subsection{Operational Definition}

2.3.1. Postspinal Back Pain. The symptom of pricking sensation or local tenderness at the site of needle insertion is characterized by tenderness without radiating pain to the buttock or/and to lower extremities and no neurological findings [16, 18, 22, 25-28].

2.3.2. Visual Analogue Scale (VAS). It is a method of pain assessment tool determined by the patient making a mark of their pain intensity on a line which is 100 millimeters long. It is a horizontal line with "no pain" at one end to "worst possible pain" at the other end of the line. It is a valid pain assessment tool [29].

No pain-----------worst imaginable pain.

In a line of $100 \mathrm{~mm}$ VAS rating, 0 to $4 \mathrm{~mm}$ can be considered no pain; 5 to $44 \mathrm{~mm}$, mild pain; 45 to $74 \mathrm{~mm}$, moderate pain; and 75 to $100 \mathrm{~mm}$, severe pain $[30,31]$.

2.3.3. Angle of Lumbar Puncture. The angle of lumbar puncture is the angle of needle bevels' with respect to spinal ligaments which is perpendicular or parallel to the fibers of supraspinous and interspinous ligaments [1].

2.3.4. Number of Punctures. It is the number procedures starting from the introduction of the spinal needle and 
ending with the removal of the stylet with anticipation of CSF flashback or the number of inserting the spinal needle through the soft tissues ligaments to perform subarachnoid block [32-34].

2.3.5. Number of Bone Contacts. It is the number of contacts of bone structures during an attempt to perform subarachnoid block [1].

2.3.6. Spinal Needle Gauges. Spinal needles of size from 23 to $29 \mathrm{G}$ are small needle gauges whereas spinal needle gauges of size from 18 to $22 \mathrm{G}$ are labeled as big needle gauges $[35,36]$.

2.3.7. Overweight and Obesity. They are defined as abnormal or excessive fat accumulation that presents a risk to health. A body mass index (BMI) over 25 to 29.9 is considered overweight, and 30 or above is obese [37].

2.4. Data Collection Procedures. Data was collected by chart review, patient interview, and through observation using a semistructured questionnaire prepared from different literature. Patients were asked whether they felt local tenderness or pain at the site of needle injection site or not. The patients who had felt pain were asked to mark on $100 \mathrm{~mm}$ horizontal line pain assessment tool (VAS score tool) to indicate the intensity of their back pain after the data collector gave them a detailed and adequate information. So, PSBP was assessed with VAS score tool whether they had felt pain or not in $24 \mathrm{hr}$, $48 \mathrm{hr}$, and $72 \mathrm{hrs}$ postoperatively in postanesthesia care units (PACU) and wards. If the study participants felt PSBP, then they were asked to mark the level of pain and the data was considered but if they did not feel pain, the data collector observed those patients every $24 \mathrm{hrs}$ until $72 \mathrm{hrs}$. The data collection procedure was continued until the estimated sample size is reached.

2.5. Data Quality Management. A half-day training was given to data collectors and supervisors about the data collection tool and how to get consent for the study. To ensure the quality of data, a pretest was done on 22 patients $(10 \%$ of the sample size) who were not included in the main study. Then, the necessary correction was done on the questionnaire for the main study. The principal investigator and supervisor checked the collected data for completeness, accuracy, and clarity. Daily supervision and feedback were done by the principal investigator and supervisors during the entire data collection period. Finally, coding, data entry, data cleaning, and crosschecking were done before data analysis.

2.6. Data Processing, Analysis, and Interpretation. This study used Epi-info and SPSS version 20 for data entry and analysis. Descriptive statistical analysis such as simple frequencies, crosstab, measures of central tendency, and measures of variability was used to describe the characteristics of participants. Then, the information was presented using frequencies, summary measures, tables, and figures.
The association between dependent and independent variables were assessed by using univariable and multivariable logistic regression. Binary logistic regression was run to see the association between each independent variable and the outcome variable at a $p$ value $<0.2$. A variable whose univariable test had a $p$ value $<0.2$ was a candidate for multiple logistic regression along with all variables. The multivariable logistic regression model was used to determine factors associated with PSBP. Adjusted odds ratio with corresponding 95\% confidence interval was computed to see the strength of association. In the multivariable analysis, a variable with a $p$ value of $<0.05$ was considered statistically significant. Hosmer Lemeshow test was also used for checking goodness of fit.

\section{Results}

3.1. Sociodemographic Characteristics of the Study Participants. A total of 215 participants were involved in this study. The highest number $72(33.5 \%)$ belongs to the age group of 26-34 years. More than two-thirds, 150 (69.8\%), of the study participants were female and around one-third, 71 (33.0\%), were housewives. Regarding their nutritional status, about $152(70.7 \%)$ of participants had a BMI of $18.7-25 \mathrm{~kg} /$ $\mathrm{m}^{2}$ and $20(9.3 \%)$ were obese $\left(\mathrm{BMI}>30 \mathrm{~kg} / \mathrm{m}^{2}\right)$ (Table 1$)$.

3.2. Prevalence of Postspinal Back Pain. The overall prevalence of PSBP in this study was 40.5\% (95\% CI: 34.0, 47.4).

Postoperative data showed the highest incidence found on the first day and the lowest was on the third day. On the first postoperative day, $39(18.1 \%)$ of the study participants $(n=215)$ experienced back pain but $81.9 \%$ of them showed no postoperative backache on day one. 20 (11.3\%) of the respondents $(n=176)$ experienced back pain on the second postoperative day. On the $3^{\text {rd }}$ postoperative day, $28(17.9 \%)$ of the participants $(n=156)$ experienced back pain (Figure 1).

The mean severity of back pain VAS score was $4.2 \pm 1.5$ SD considering the total of patients who had developed back pain $(n=87)$. The mean intensity of the pain VAS score was $4.2 \pm 1.4 \mathrm{SD}$ in the first postoperative day $(n=39), 4.3 \pm 1.7$ $\mathrm{SD}$ in the second postoperative day $(n=20)$, and $4.0 \pm 1.6 \mathrm{SD}$ in the third postoperative day $(n=28)$ (Figure 2).

Among the participants, the highest percentage of PSBP (80\%) happened in patients who had BMI $>30 \mathrm{~kg} / \mathrm{m}^{2}$ and the lowest percentage $(11.8 \%)$ happened in patients who had spinal anesthesia with small size needle (Table 2). According to the experience of the anesthetists, the highest proportion (45.7\%) of PSBP happened in patients who have had spinal anesthesia with anesthesia students.

PSBP was found to be more common in patients whose surgical procedure took greater than one hour (47.9\%) than in patients whose surgical procedure took less than one hour $(34.3 \%)$. PSBP was also more common in patients who had surgery on supine and lithotomy positions (Table 2).

Both the number of attempts of lumbar puncture and the number of bone contacts during lumbar puncture had a direct relationship with the incidence of postspinal backache. An attempt of lumbar puncture $\geq 3$ times was found to 
TABLE 1: Sociodemographic characteristics of the study participants who underwent the surgical procedure under spinal anesthesia at the University of Gondar Comprehensive and Specialized Hospital from March to May $2020(n=215)$.

\begin{tabular}{|c|c|c|}
\hline Variable & Frequency & Percentage (\%) \\
\hline \multicolumn{3}{|l|}{ Age (years) } \\
\hline $17-25$ & 55 & 25.6 \\
\hline $26-34$ & 72 & 33.5 \\
\hline $35-41$ & 36 & 16.7 \\
\hline$>41$ & 52 & 24.2 \\
\hline \multicolumn{3}{|l|}{ Sex } \\
\hline Female & 150 & 69.8 \\
\hline Male & 65 & 30.2 \\
\hline \multicolumn{3}{|l|}{ Ethnicity } \\
\hline Amhara & 195 & 90.7 \\
\hline Oromo & 5 & 2.3 \\
\hline Other* & 15 & 7.0 \\
\hline \multicolumn{3}{|l|}{ Educational status } \\
\hline Unable to read and write & 63 & 29.3 \\
\hline Able to read and write & 152 & 70.7 \\
\hline \multicolumn{3}{|l|}{ Occupation } \\
\hline Student & 18 & 8.4 \\
\hline Teacher & 25 & 11.6 \\
\hline Merchant & 39 & 18.1 \\
\hline Housewife & 71 & 33.0 \\
\hline Farmer & 43 & 20.0 \\
\hline Other ${ }^{* *}$ & 19 & 8.9 \\
\hline \multicolumn{3}{|l|}{ BMI } \\
\hline $18.7-25 \mathrm{~kg} / \mathrm{m}^{2}$ & 152 & 70.7 \\
\hline $25-29.9 \mathrm{~kg} / \mathrm{m}^{2}$ & 43 & 20 \\
\hline$\geq 30 \mathrm{~kg} / \mathrm{m}^{2}$ & 20 & 9.3 \\
\hline \multicolumn{3}{|l|}{ ASA status } \\
\hline ASA I & 55 & 25.6 \\
\hline ASA II & 135 & 62.8 \\
\hline ASA III & 25 & 11.6 \\
\hline
\end{tabular}

$\mathrm{BMI}=$ body mass index, ASA status = American Society of Anesthesiologist. *(Other ethnicity): Tigre, Wollita, Gumez, Hadire, Somali, and Agew. **(Other occupation): driver, bank accountant, secretary, unemployed, daily labor, cleaner, gardener, police, soldier, engineer, health care provider, manager, and politician.

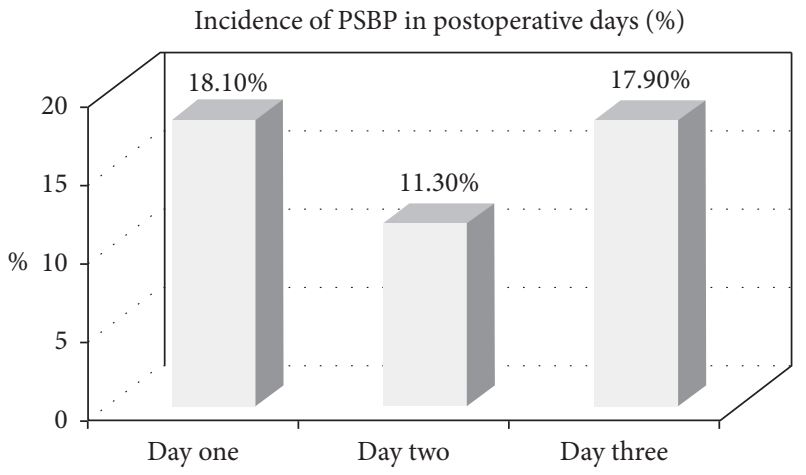

Figure 1: Prevalence of back pain on the three postoperative days at the University of Gondar Comprehensive and Specialized Hospital, Northwest Ethiopia, from March to May $2020(n=87)$.

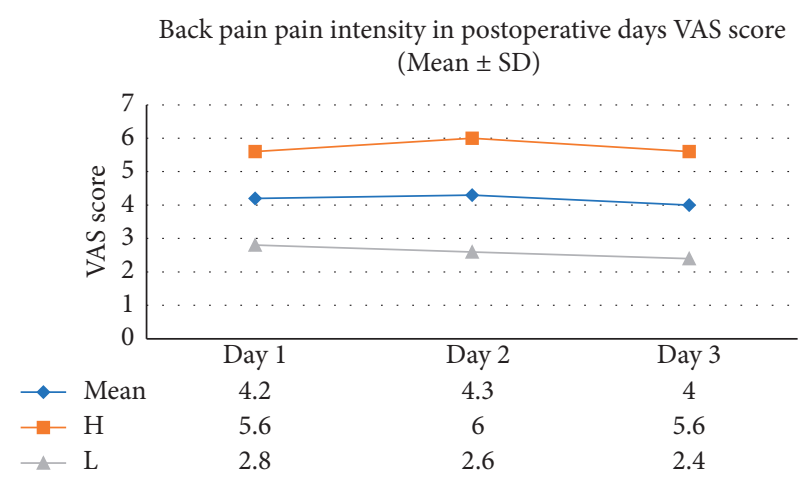

FIGURE 2: Severity of back pain on the three postoperative days at the University of Gondar Comprehensive and Specialized Hospital, North West Ethiopia, from March to May $2020(n=87)$.

be the highest incidence of PSBP (73.8\%). In addition, those participants who had a higher number of bone contacts during spinal anesthesia had developed more back pain (Table 2).

The incidence was high in patients who had spinal anesthesia at the level of lumbar puncture interspace $\mathrm{L}_{2}-\mathrm{L}_{3}$ $(78.9 \%)$ and back pain happened higher when the angle of the needle was perpendicular (57.8\%) to the skin than was parallel (33.1\%) to the skin (Table 2).

3.3. Factors Associated with Postspinal Back Pain. Both univariable and multivariable logistic regression analyses were done to see factors associated with PSBP. Variables like body mass index (BMI), ASA status, spinal needle size, number of attempts, number of bone contacts, angle of the needle, spinal interspace, history and numbers of previous SA exposures, and the presence of skin infiltration had a $\mathrm{p}$ value of $<0.2$ in the binary logistic regression analysis.

Finally, spinal needle size, number of attempts, and the number of bone contacts were significantly associated with PSBP in the multivariable logistic regression analysis (Table 3).

Accordingly, overweight patients were fourfold more likely to develop PSBP than patients with a BMI of $<25 \mathrm{~kg} /$ $\mathrm{m}^{2}[\mathrm{AOR}=3.8$ (95\% CI: 1.47, 9.96)]. Similarly, obese patients were 5 times more likely to develop PSBP than patients with a BMI of $<25 \mathrm{~kg} / \mathrm{m}^{2}$ [AOR 4.9 (95\% CI: 1.19, 20.43)]. Patients who underwent surgery with big spinal needle gauges were 6 times more likely to develop PSBP than small gauge needles $[\mathrm{AOR}=5.9$ (95\% CI: 1.04, 33.46)].

The number of attempts of lumbar puncture was also significantly associated with PSBP. Patients who had 2-time attempt were 4 times more likely to develop PSBP than patients who had only a single attempt $[\mathrm{AOR}=3.6(95 \% \mathrm{CI}$ : $1.29,10.42)]$ and patients who had more than 3 -time attempt also were 5 times more likely to develop PSBP than patients who had only a single attempt $[\mathrm{AOR}=4.9$ (95\% CI: 1.63 , 15.23)]. 
TABLE 2: Associated factors with PSBP of the study participants at the University of Gondar Comprehensive and Specialized Hospital, Northwest Ethiopia, from March to May $2020(n=215)$.

\begin{tabular}{|c|c|c|c|}
\hline \multirow{2}{*}{ Variables } & \multirow{2}{*}{ Frequency } & \multicolumn{2}{|c|}{ PSBP } \\
\hline & & Yes $(\%)$ & No $(\%)$ \\
\hline \multicolumn{4}{|l|}{ BMI } \\
\hline $18.7-25 \mathrm{~kg} / \mathrm{m}^{2}$ & 152 & $41(27.0)$ & $111(73.0)$ \\
\hline $25-29.9 \mathrm{~kg} / \mathrm{m}^{2}$ & 43 & $30(69.8)$ & $13(30.2)$ \\
\hline$\geq 30 \mathrm{~kg} / \mathrm{m}^{2}$ & 20 & $16(80.0)$ & $4(20)$. \\
\hline \multicolumn{4}{|l|}{ Experience of anesthetist } \\
\hline Student & 35 & $16(45.7)$ & $19(54.3)$ \\
\hline $1-4$ years & 71 & $28(39.4)$ & $43(60.6)$ \\
\hline$>4$ years & 109 & $43(39.4)$ & $66(60.6)$ \\
\hline \multicolumn{4}{|l|}{ Previous SA } \\
\hline No & 151 & $48(31.8)$ & $103(68.2)$ \\
\hline Yes & 64 & $39(60.9)$ & $25(39.1)$ \\
\hline \multicolumn{4}{|c|}{ Number of exposures to SA $(n=64)$} \\
\hline One & 40 & $23(57.5)$ & $17(42.5)$ \\
\hline Two & 20 & $13(65)$ & $7(35)$ \\
\hline$>$ two & 4 & $3(75)$ & $1(25)$ \\
\hline \multicolumn{4}{|l|}{ Type of surgery } \\
\hline Obstetrics & 106 & $47(44.3)$ & $59(55.7)$ \\
\hline Gynecology & 28 & $5(17.9)$ & $23(82.1)$ \\
\hline Orthopedic & 47 & $18(38.3)$ & $29(61.7)$ \\
\hline Urology & 15 & $7(46.7)$ & $8(53.3)$ \\
\hline Other & 19 & $10(52.6)$ & $9(47.4)$ \\
\hline \multicolumn{4}{|l|}{ Urgency of surgery } \\
\hline Elective & 79 & $30(38)$ & $49(62)$ \\
\hline Emergency & 136 & $57(41.9)$ & $79(58.1)$ \\
\hline \multicolumn{4}{|l|}{ Duration of surgery } \\
\hline$<30$ minutes & 20 & $7(35)$ & $13(65)$ \\
\hline $30-60$ minutes & 99 & $34(34.3)$ & $65(65.7)$ \\
\hline$>60$ minutes & 96 & $46(47.9)$ & $50(52.1)$ \\
\hline \multicolumn{4}{|l|}{ Surgical position } \\
\hline Supine & 193 & $79(40.9)$ & $114(59.1)$ \\
\hline Lateral & 12 & $4(33.3)$ & $8(66.7)$ \\
\hline Lithotomy & 10 & $4(40)$ & $6(60)$ \\
\hline \multicolumn{4}{|c|}{ Presence of skin infiltration } \\
\hline Yes & 145 & $49(33.8)$ & $96(66.2)$ \\
\hline No & 70 & $38(54.3)$ & $32(45.7)$ \\
\hline \multicolumn{4}{|l|}{ Number of attempts } \\
\hline One & 99 & $11(11.1)$ & $88(88.9)$ \\
\hline Two & 55 & $31(56.4)$ & $24(43.6)$ \\
\hline$>$ two & 61 & $45(73.8)$ & $16(26.2)$ \\
\hline \multicolumn{4}{|l|}{ Number of bone contacts } \\
\hline No contact & 114 & $16(14)$ & $98(86)$ \\
\hline One & 38 & $19(50.0)$ & $19(50.0)$ \\
\hline$\geq$ Two & 63 & $52(82.5)$ & $11(17.5)$ \\
\hline \multicolumn{4}{|l|}{ Size of needles } \\
\hline Big needle $(18-22 \mathrm{G})$ & 197 & $85(43.1)$ & $112(56.9)$ \\
\hline Small needle $(23-29 G)$ & 18 & $2(11.1)$ & $16(88.9)$ \\
\hline \multicolumn{4}{|c|}{ Level of interspace puncture } \\
\hline $\mathrm{L}_{2}-\mathrm{L}_{3}$ & 19 & $15(78.9)$ & $4(21.1)$ \\
\hline $\mathrm{L}_{3}-\mathrm{L}_{4}$ & 169 & $55(32.5)$ & $114(67.5)$ \\
\hline $\mathrm{L}_{4}-\mathrm{L}_{5}$ & 27 & $17(63)$ & $10(37)$ \\
\hline \multicolumn{4}{|c|}{ Angle of the spinal needle to the skin } \\
\hline Parallel & 151 & $50(33.1)$ & $101(66.9)$ \\
\hline Perpendicular & 64 & $37(57.8)$ & $27(57.8)$ \\
\hline Position of SA & & & \\
\hline
\end{tabular}

TABle 2: Continued.

\begin{tabular}{cccc}
\hline \multirow{2}{*}{ Variables } & \multirow{2}{*}{ Frequency } & \multicolumn{2}{c}{ PSBP } \\
& & Yes (\%) & No (\%) \\
\hline Sitting & 206 & $81(39.1)$ & $125(60.7)$ \\
Lateral & 9 & $6(66.7)$ & $3(33.3)$ \\
\hline
\end{tabular}

PSBP $=$ postspinal back pain, $\mathrm{BMI}=$ body mass index, $\mathrm{kg} / \mathrm{m}^{2}=$ kilogram per meter square. $\mathrm{SA}=$ spinal anesthesia, $\mathrm{G}=$ gauge, $\mathrm{L}=$ lumbar. Other procedures: foreign body removal, hernia repair, fistula repair, perianal abscess, psoas abscess, foreigners gangrene, and hemoroidectomy.

Finally, patients who had a single bone contact were 3 times more likely to develop PSBP than patients who had no bone contact $[\mathrm{AOR}=3.1$ (95\% CI: 1.14, 8.45)]. Likewise, patients who had greater than a two-time number of bone contacts during the procedure were 8 times more likely to develop PSBP than patients who had no bone contact $[\mathrm{AOR}=7.6$ (95\% CI; 2.60, 22.43)] (Table 3).

\section{Discussion}

One of the common complications of spinal anesthesia in clinical practice is postoperative back pain. The reduction of this pain is mandatory to increase the quality of life, expand anesthesia outcomes, and improve patient satisfaction $[3,6]$.

In the current study, the overall prevalence of postspinal back pain was $40.5 \%$ (95\% CI: $34.0-48.4$ ). This result was consistent with the study done in Germany (40\%) [21]. However, the current finding is higher than the reports in the Republic of Korea (32\%) [38]. This might be due to the fact that patients who had multiple lumbar puncture attempts (>3 times) were included in our study. During multiple lumbar puncture, there might be a cutting down of tissues and rupture of smaller blood vessels and nerves which causes back pain. This study's findings were also higher compared with the studies conducted in Europe (17\%) [20] and Iran (5.8\%) [39]. This discrepancy might be due to the fact that bigger sized spinal needles were used commonly in the study setup. Thus, bigger size spinal needles may damage different tissues and matters which might be subject to back pain.

In this study, the distributions of the prevalence of PSBP across postoperative days were analysed. The prevalence of PSBP was $18.1 \%$ (95\% CI: 13.2, 23.1) on the first day, $11.3 \%$ $(95 \%$ CI: $6.0,12.8)$ on the $2^{\text {nd }}$ day, and $17.9 \%$ (95\% CI: 8.6 , 18.1) on the $3^{\text {rd }}$ day. This finding was in consistence with the study conducted in Iran on the $1^{\text {st }}$ postoperative day $(16.7 \%)$ [39]. However, this finding was lower compared to the studies conducted in China (38\%) [22] and Turkey (29.3\%) [1] on the $1^{\text {st }}$ postoperative day. The reason for this difference might be due to the fact that patients who had preexisting back pain were excluded from our study.

A study conducted in Asella, Ethiopia, showed an incidence of $38,29.9$, and $31.6 \%$ of patients developed back pain on the $1^{\text {st }}, 2^{\text {nd }}$, and $3^{\text {rd }}$ postoperative days, respectively [4]. This might be due to the fact that they have used big spinal needles (18-21G) and also excluded patients with preexisting back pain. 
TABLE 3: Factors associated with PSBP in patients who underwent the surgical procedure under spinal anesthesia, Northwest Ethiopia, from March to May $2020(n=215)$.

\begin{tabular}{|c|c|c|c|c|}
\hline \multirow{2}{*}{ Variables } & \multicolumn{2}{|c|}{ PSBP } & \multicolumn{2}{|c|}{ OR $(95 \% \mathrm{CI})$} \\
\hline & Yes $(\%)$ & No $(\%)$ & COR & AOR \\
\hline \multicolumn{5}{|l|}{ BMI } \\
\hline $18.7-25 \mathrm{~kg} / \mathrm{m}^{2}$ & $41(27)$ & $111(73)$ & 1.00 & 1.00 \\
\hline $25-29.9 \mathrm{~kg} / \mathrm{m}^{2}$ & $30(69.8)$ & $13(30.2)$ & $6.2(2.97,13.13)^{*}$ & $3.8(1.48,9.96)^{*}$ \\
\hline$\geq 30 \mathrm{~kg} / \mathrm{m}^{2}$ & $16(80)$ & $4(20)$ & $10.8(3.42,34.29)^{*}$ & $4.9(1.19,20.43)^{*}$ \\
\hline \multicolumn{5}{|l|}{ Needle size } \\
\hline Small needle (23-29G) & $2(11.1)$ & $16(88.9)$ & 1.00 & 1.00 \\
\hline Big needle $(18-22 \mathrm{G})$ & $85(43.1)$ & $112(56.9)$ & $6.1(1.36,27.12)^{*}$ & $5.9(1.04,33.46)^{*}$ \\
\hline \multicolumn{5}{|c|}{ Number of attempts of lumbar puncture } \\
\hline Once & $11(11.1)$ & $88(88.9)$ & 1.00 & 1.00 \\
\hline Twice & $31(56.4)$ & $24(43.6)$ & $10.3(4.53,23.5)^{*}$ & $3.6(1.29,10.42)^{*}$ \\
\hline$\geq$ three times & $45(73.8)$ & $16(26.2)$ & $22.5(9.64,52.51)^{*}$ & $4.9(1.63,15.23)^{*}$ \\
\hline \multicolumn{5}{|c|}{ Number of bone contacts during spinal anesthesia } \\
\hline No contact & $16(14.0)$ & $98(86.0)$ & 1.00 & 1.00 \\
\hline Once & $19(50)$ & $19(50)$ & $6.1(2.68,14.0)^{*}$ & $3.1(1.14 .8 .45)$ \\
\hline$\geq$ Twice & $52(82.5)$ & $11(17.5)$ & $28.9(12.52,66.94)^{*}$ & $7.6(2.60,22.43)^{*}$ \\
\hline
\end{tabular}

$\mathrm{OR}=$ odd ratio, $\mathrm{CI}=$ confidence interval, $\mathrm{COR}=$ crude odds ratio, $\mathrm{AOR}=$ adjusted odds ratio, $\mathrm{PSBP}=$ postspinal back pain, and $\mathrm{BMI}=$ body mass index.

* Significantly associated with PSBP, 1: reference.

Different studies showed that PSBP mostly occurred during the use of bigger size spinal needles than smaller ones $[4,12,17,18]$. In this study, also spinal needle size had a strong association with PSBP. Thus, patients who were given SA using a big spinal needle were 5.9 times more likely to develop PSBP than patients who received SA using small size spinal needles (AOR $=5.9$ (95\% CI: 1.04, 33.46). This might be due to the reason that bigger size spinal needles have a wide area penetration starting from skin to subarachnoid space including matters leading to PSBP. Another study done in Ethiopia showed that patients who had a lumbar puncture with $18 \mathrm{G}$ needle were four times more likely to develop PSBP than patients who had a lumbar puncture with $21 \mathrm{G}$ needle size. [17]. The possible reason for this variation might be due to the classification of spinal needle sizes. Because the study compared the $18 \mathrm{G}$ and $21 \mathrm{G}$ size spinal needles, this study classified the size of spinal needle sizes into big (18-22G) and small size (23-29G). [36].

Soft tissue damage during spinal anesthesia intervention had been studied in previous studies and found to be one of the risk factors to develop back pain following spinal anesthesia $[1,12,18]$. This might be related to the number of lumbar puncture attempts. In this study, the number of lumbar puncture attempts had a direct relationship with the development of PSBP. Thus, patients who had two attempts of a lumbar puncture during spinal anesthesia procedure were 3.6 times more vulnerable to develop PSBP than those who had one lumbar puncture attempt. On the other hand, those who had an attempt of three and more were 4.9 times more likely to develop PSBP. This might be due to repeated tissue damage and even might have nerve damage or touch which end up PSBP. Some of the studies shared that the number of lumbar puncture attempts during spinal anesthesia increases the risk of trauma and possible back pain after a surgical procedure $[1,4,17,40]$.
The likelihood to developed PSBP in patients who had single and $\geq 2$-time bone contact during the procedure of spinal anesthesia wes 3 times ( $\mathrm{AOR}=3.1$; CI: 1.14, 8.45) and 7.6 times (AOR $=7.6 ; 95 \% \mathrm{CI}: 2.60,22.43$ ), respectively, more than patients who had no bone contact. This might be also due to soft tissue damage, bone scratch, and nerve injuries during bone contacts. This association is in line with the studies done in Turkey $[1,16]$.

Body mass index was associated with PSBP and supported by other studies $[1,41]$. The present study found that patients who were overweight and obese were more likely to develop PSBP than patients with normal BMI. One of the possible reasons might be due to repeated lumbar puncture and multiple attempts during spinal anesthesia because of difficulties to identify the exact landmark in patients who had higher BMI [16, 42, 43].

Finally, as a limitation, even though this study investigates the unseen problem after spinal anesthesia at the University of Gondar Comprehensive Specialized Hospital, it includes a smaller sample size due to the small number of patient flow due to the pandemic of Covid-19. In addition, patients were followed up for only three postoperative days but they may develop postspinal back pain after they discharge from the hospital. On the other hand, the visual analogue scale score was difficult to understand for most of the study subjects to evaluate the severity of pain since most of them were illiterate.

\section{Conclusion}

This study confirms that the overall incidence of back pain is high as compared to most studies. Body mass index, the size of spinal needle, the number of attempts, and the number of bone contacts are significantly associated with the incidence of back pain following spinal anesthesia. Hence, health professionals should minimize the number of attempts and bone contacts during lumbar puncture and choose smaller 
spinal needles to reduce the prevalence of postspinal back pain. Finally, conducting a similar study to assess the longterm occurrence of postspinal back pain is recommended.

\section{Abbreviations}

$\begin{array}{ll}\text { AOR: } & \text { Adjusted odds ratio } \\ \text { ASA: } & \text { American Society of Anesthesiologist } \\ \text { BMI: } & \text { Body mass index } \\ \text { CI: } & \text { Confidence interval } \\ \text { COR: } & \text { Crude odds ratio } \\ \text { PACU: } & \text { Postanesthesia care unit } \\ \text { PSBP: } & \text { Postspinal back pain } \\ \text { SA: } & \text { Spinal anesthesia } \\ \text { SD: } & \text { Standard deviation } \\ \text { SPSS: } & \text { Statistical package for social sciences } \\ \text { VAS: } & \text { Visual analogue scale. }\end{array}$

\section{Data Availability}

Due to ethical restrictions and privacy concerns, a dataset is available upon request from the corresponding author, Abraham Tarekegn: abrahamtm2006@gmail.com.

\section{Ethical Approval}

Ethical clearance was obtained from the ethical review committee of the School of Medicine, College of Medicine and Health Science, University of Gondar. Confidentiality was guaranteed by avoiding personal identification and keeping the completed questionnaires locked. During assessment, if the data collector found a patient had any pain whether on the site of injection or wound pain or other, he would inform the responsible healthcare practitioner to be treated.

\section{Conflicts of Interest}

The authors declare that there are no conflicts of interest regarding this paper.

\section{Authors' Contributions}

TGZ conceived the study, developed the tool, coordinated the data collection activity, and carried out the statistical analysis. YAF and NSE participated in the design of the study, tool development, data collection supervision, and drafting the manuscript. ATM participated in the design of the study and tool development, performed the statistical analysis, and reviewed and edited the manuscript. All authors read and approved the final manuscript.

\section{Acknowledgments}

The authors would like to acknowledge the University of Gondar for approval of ethical clearance. The authors' special gratitude goes to study participants and data collectors for their voluntary participation.

\section{References}

[1] Z. T. Tekgül, S. Pektaş, M. Turan, Y. Karaman, M. Çakmak, and M. Gönüllü, "Acute back pain following surgery under spinal anesthesia," Pain Practice, vol. 15, no. 8, pp. 706-711, 2015.

[2] B. Shikur, A. Marye, and E. Mesfin, "Spinal anesthesia for cesarean delivery at two teaching hospitals in Addis Ababa, Ethiopia," Ethiopian Medical Journal, vol. 56, no. 2, pp. 133-140, 2018.

[3] T. M. Cook, D. Counsell, and J. A. W. Wildsmith, "Major complications of central neuraxial block: report on the third national audit project of the royal College of anaesthetists $\dagger$," British Journal of Anaesthesia, vol. 102, no. 2, pp. 179-190, 2009.

[4] M. Joudi, M. Fathi, S. J. Amin Dalili, A. M. Ardabili, M. Akhondi, and A. Izanloo, "The association of anesthetic method with developing back pain after lower extremity operations," Anesthesiology and Pain Medicine, vol. 4, no. 5, 2014.

[5] K. Schwabe and H.-B. Hopf, "Persistent back pain after spinal anaesthesia in the non-obstetric setting: incidence and predisposing factors," British Journal of Anaesthesia, vol. 86, no. 4, pp. 535-539, 2001.

[6] J. S. Lee, "Spinal anesthesia: how can we improve patient satisfaction?" Korean Journal of Anesthesiology, vol. 59, no. 4, p. 231, 2010.

[7] V. B. Patel, R. Wasserman, and F. Imani, "Interventional therapies for chronic low back pain: a focused review (efficacy and outcomes)," Anesthesiology and Pain Medicine, vol. 5, no. 4, Article ID e29716, 2015.

[8] R. Shiri, J. Karppinen, P. Leino-Arjas, S. Solovieva, and E. Viikari-Juntura, "The association between smoking and low back pain: a meta-analysis," The American Journal of Medicine, vol. 123, no. 1, pp. 87.e7-87.e35, 2010.

[9] J. S. Williams, N. Ng, K. Peltzer et al., "Risk factors and disability associated with low back pain in older adults in lowand middle-income countries. Results from the WHO study on global Ageing and adult health (SAGE)," PLoS One, vol. 10, no. 6, Article ID 127880, 2015.

[10] R. E. Docking, J. Fleming, C. Brayne et al., "Epidemiology of back pain in older adults: prevalence and risk factors for back pain onset," Rheumatology (Oxford, England), vol. 50, no. 9, pp. 1645-1653, 2011.

[11] F. Balagué, A. F. Mannion, F. Pellisé, and C. Cedraschi, "Nonspecific low back pain," The Lancet, vol. 379, no. 9814, pp. 482-491, 2012.

[12] W. J. Rhee, C. J. Chung, Y. H. Lim, K. H. Lee, and S. C. Lee, "Factors in patient dissatisfaction and refusal regarding spinal anesthesia," Korean Journal of Anesthesiology, vol. 59, no. 4, p. 260, 2010.

[13] M. M. K. Haghighi, A. Mohammadzadeh, H. Etehad, M. Soleymanha, and A. Mirbolook, "Evaluation of correlative factor of backache and headache after spinal anesthesia in orthopedic surgery," Journal of Guilan University of Medical Sciences, vol. 21, no. 82, pp. 31-38, 2012.

[14] R. R. Brooks, C. Oudekerk, R. L. Olson, C. Daniel, C. Vacchiano, and J Maye, "The effect of spinal introducer needle use on postoperative back pain," AANA Journal, vol. 70, no. 6, pp. 449-452, 2002.

[15] R. D. Meucci, A. G. Fassa, and N. M. X. Faria, "Prevalence of chronic low back pain: systematic review," Revista de saude publica, vol. 49, p. 73, 2015. 
[16] H. T. Benzon, Y. G. Asher, and C. T. Hartrick, "Back pain and neuraxial anesthesia," Anesthesia \& Analgesia, vol. 122, no. 6, pp. 2047-2058, 2016.

[17] A. N. ABaea, "Prevalence and risk factors of acute backache after spinal anesthesia in surgical procedures at asella teaching and referal hospital, asella, Ethiopia," International Journal of Medicine and Medical Sciences, vol. 11, pp. 1-10, 2019.

[18] M. K. Rafique and A. Taqi, "The causes, prevention and management of post spinal backache: an overview," Anaesthesia, Pain \& Intensive Care, vol. 15, no. 1, pp. 65-69, 2011.

[19] P. H. Pan, R. Fragneto, C. Moore, and V. Ross, "Incidence of postdural puncture headache and backache, and success rate of dural puncture: comparison of two spinal needle designs," Southern Medical Journal, vol. 97, no. 4, pp. 359-363, 2004.

[20] F. H. Duits, P. Martinez-Lage, C. Paquet et al., "Performance and complications of lumbar puncture in memory clinics: results of the multicenter lumbar puncture feasibility study," Alzheimer's \& Dementia: The Journal of the Alzheimer's Association, vol. 12, no. 2, pp. 154-163, 2016.

[21] F. Ebinger, C. Kosel, J. Pietz, and D. Rating, "Headache and backache after lumbar puncture in children and adolescents: a prospective study," Pediatrics, vol. 113, no. 6, p. 1588, 2004.

[22] W. Gao, Y. Ren, and G. X. Cui, "Dexamethasone added to local lidocaine for infiltration along the spinal-epidural needle pathway decreases incidence and severity of backache after gynecological surgery," Medical Science Monitor: International Medical Journal of Experimental and Clinical Research, vol. 21, p. 821, 2015.

[23] U. M. Makoko, L. M. Modiba, and D. K. Nzaumvila, "Satisfaction with spinal anaesthesia for Caesarean section at Tembisa Hospital, South Africa: a cross-sectional study," South African Family Practice, vol. 61, no. 2, pp. 39-47, 2019.

[24] N. Farhat, R. Fu, and S. K. Janjua, "Frequency of persistant backache in patients of spinal anaesthesia in the absence of prior history of backache," Pakistan Armed Forces Medical Journal, vol. 63, no. 2, p. 127, 2013.

[25] A. T. Patel and A. A. Ogle, "Diagnosis and management of acute low back pain," American Family Physician, vol. 61, no. 6, pp. 1779-1790, 2000.

[26] K. H. Kumar and P. Elavarasi, "Definition of pain and classification of pain disorders," Journal of Advanced Clinical \& Research Insights, vol. 3, no. 3, pp. 87-90, 2016.

[27] A. C. D. C. Williams and K. D. Craig, "Updating the definition of pain," Pain, vol. 157, no. 11, pp. 2420-2423, 2016.

[28] H. Vernon, "What is different about spinal pain?" Chiropractic \& Manual Therapies, vol. 20, no. 1, p. 22, 2012.

[29] N. Crichton, "Visual analogue scale (VAS)," Journal of Clinical Nursing, vol. 10, no. 5, pp. 706-6, 2001.

[30] G. A. Hawker, S. Mian, T. Kendzerska, and M. French, "Measures of adult pain: visual analog scale for pain (VAS pain), numeric rating scale for pain (NRS pain), McGill pain questionnaire (MPQ), short-form McGill pain questionnaire (SF-MPQ), chronic pain grade scale (CPGS), short form-36 bodily pain scale (SF," Arthritis Care \& Research, vol. 63, no. S11, pp. S240-S252, 2011.

[31] M. Jensen, C. Chen, and A. M. Brugger, "Interpretation of visual analog scale ratings and change scores: a reanalysis of two clinical trials of postoperative pain," The Journal of Pain, vol. 4, no. 7, pp. 407-414, 2003.

[32] H. Liu, M. Brown, L. Sun et al., "Complications and liability related to regional and neuraxial anesthesia," Best Practice \& Research Clinical Anaesthesiology, vol. 33, no. 4, pp. 487-497, 2019.
[33] M. A. Headache, "Classification committee of the international headache society (IHS) the international classification of headache disorders," Cephalalgia, vol. 38, no. 1, pp. 1-211, 2018.

[34] AA. K. Post, "Dural puncture headache (PDPH) and associated factors after spinal anesthesia among patients in university of gondar referral and teaching hospital, gondar, North west Ethiopia," Journal of Anesthesia \& Clinical Research, vol. 6, no. 6, 2015.

[35] L. C. Tsen and D. L. Hepner, "Needles used for spinal anesthesia," Expert Review of Medical Devices, vol. 3, no. 4, pp. 499-508, 2006.

[36] F. Tarekegn, S. Eshetie, A. Aregawi, and K. Moges, "Assessment of the prevalence and associated risk factors of post dural puncture headache (PDPH) after cesarean section delivery under spinal anesthesia," Journal of Anesthesia \& Critical Care Open Access, vol. 8, no. 6, Article ID 00330, 2017.

[37] M. De Onis, World Health Organization Reference Curves, European Childhood Obesity Group, Rome, Italy, 2015.

[38] J. H. Lee, D. H. Yoon, and B. H. Heo, "Incidence of newly developed postoperative low back pain with median versus paramedian approach for spinal anesthesia," Korean Journal of Anesthesiology, vol. 73, no. 6, pp. 518-524, 2020.

[39] M. Forozeshfard, E. Jahan, J. Amirsadat, and R. Ghorbani, "Incidence and factors contributing to low Back pain in the nonobstetrical patients operated under spinal anesthesia: a prospective 1-year follow-up study," Journal of PeriAnesthesia Nursing, vol. 35, no. 1, pp. 34-37, 2020.

[40] N. Siddiqui, Z. Friedman, A. McGeer, A. Yousefzadeh, J. C. Carvalho, and S. Davies, "Optimal hand washing technique to minimize bacterial contamination before neuraxial anesthesia: a randomized control trial," International Journal of Obstetric Anesthesia, vol. 29, pp. 39-44, 2017.

[41] S. M. Hakim, S. Narouze, N. N. Shaker, and M. A. Mahran, "Risk factors for new-onset persistent low-back pain following nonobstetric surgery performed with epidural anesthesia," Regional Anesthesia and Pain Medicine, vol. 37, no. 2, pp. 175-182, 2012.

[42] I. Heuch, I. Heuch, K. Hagen, and J.-A. Zwart, "Body mass index as a risk factor for developing chronic low back pain," Spine, vol. 38, no. 2, pp. 133-139, 2013.

[43] S. R. Thomas, D. R. Jamieson, and K. W. Muir, "Randomised controlled trial of atraumatic versus standard needles for diagnostic lumbar puncture," BMJ, vol. 321, no. 7267, pp. 986-990, 2000. 